\title{
Structural Health Monitoring Sensor based on a Flexible Microstrip Patch Antenna
}

\author{
Hamse Abdillahi Haji Omer, Saidatul Norlyana Azemi, Azremi Abdullah Al-Hadi, Ping Jack Soh, \\ Mohd Faizal Jamlos \\ Advanced Communication Engineering Centre (ACE) CoE, School of Computer and Communication Engineering, \\ Universiti Malaysia Perlis (UniMAP), Pauh Putra, Arau 02600, Malaysia.
}

\begin{tabular}{l} 
Article Info \\
\hline Article history: \\
Received Jan 15, 2018 \\
Revised Mar 12, 2018 \\
Accepted Mar 28, 2018 \\
\hline
\end{tabular}

Keywords:

Flexible Antenna

Monintoring

Patch Antenna

SHM

Strain Sensor

\begin{abstract}
A microstrip patch antenna strain sensor operating at dual frequencies $1.8 \mathrm{GHz}$ and $2.4 \mathrm{GHz}$ have been designed based on the relation between the resonant frequency and the strain applied to it. Felt substrate with a height of $3 \mathrm{~mm}$ and dielectric constant of 1.44 and shield conductor are used for the design of this antenna. Testing results show that the resonant frequency of the microstrip patch antenna is $1.78 \mathrm{GHz}$ and $2.4 \mathrm{GHz}$, which agrees with the simulation. The resonant frequency of the microstrip patch antenna increases linearly with the increase of the applied strain. This microstrip patch antenna strain sensor can be integrated with other components easily and have a great potential applications in structural health monitoring systems.
\end{abstract}

Copyright $(2018$ Institute of Advanced Engineering and Science. All rights reserved.

Corresponding Author:

Mohd Faizal Jamlos,

School of Computer and Communication Engineering,

Universiti Malaysia Perlis (UniMAP),

Pauh Putra, Arau 02600, Malaysia.

\section{INTRODUCTION}

During the past few decades there have been significant development in civil industries, aerospace and marines. These advances include new manufacturing techniques, new components, devices related to computational software and new design process. At the side of aerospace one of the main developments is the usage of highly advanced composite materials and when we compare these material with the other material used for aerospace, they have a lot of advantages, like good electromagnetic properties which makes them applicable for multifunctional applications in both military aircrafts and commercial [1].

On the other hand composite materials have introduced new complexity in health and monitoring management for civil structures, marine and aerospace. These draw backs are new form of destruction such as fibre damage, delamination and deboning which improved the need for trustworthy and perfect damage monitoring technique. Structural health monitoring is a new technology which provides systems that are capable of constantly monitoring structures for damage with minimal human mediation. Structural health monitoring are their initial phases of improvement and require advanced technology to use them in real structure [2]. The objective of structural health monitoring systems is to decrease maintenance costs, to reduce overall of ownership of a vehicle, at the same time developing safety and reliability. The development of safety is strong motivation in structural health monitoring, especially after several accidents happen because of [3]: 1. Insufficient maintenance, for example at side of aeronautic which is flight related field see Figure 1 or the collapse of Mianus River Bridge at side of civil engineering field. 2. Oil-controlled production process, for example, the Injak bridge collapse see Figure 1(b). In both fields the obstacles of aging structures was exposed and subsequent programs were recognized and established. 
Although there are a lot of works and researches that has been done in wireless sensors and their application in structural health monitoring, all these technologies still have room for improvement. These disadvantages include all these systems require a battery which has a restricted life time, require sensors which are independent from each other and also require antenna that increases the complexity, size of the sensor unit, and weight. It is also costly because they require special skills to fabricate the sensor, and finally require for a wireless sensor network which need complex software and data acquisition units (DAQ). Mostly, all the methods mentioned above is a wired sensors. These sensors have many disadvantages such as the need for installation during building. Wires also limit the structures' functionality, add more complexity to it and increase the heaviness of the structure. Therefore, a new design of technologies is becoming necessary for civil structural health monitoring (SHM)[4-8].

The goal of this project is to investigate and analyses the effectiveness of a wireless strain sensor using rectangular Microstrip patch antennas. Utilizing Microstrip patch antenna is a new technologies which eliminates complex wiring networks in structural health monitoring system and becomes a new area of research. Figure 1 shows Spectacular accidents have motivated the community to improve safety [9]. Figure 2 shows the concept of wireless SHM sensors using a microstrip patch antenna. The principle of wireless SHM sensors using microstrip patch antenna is based on the resonance frequency shift associated with the strain applied to the building.

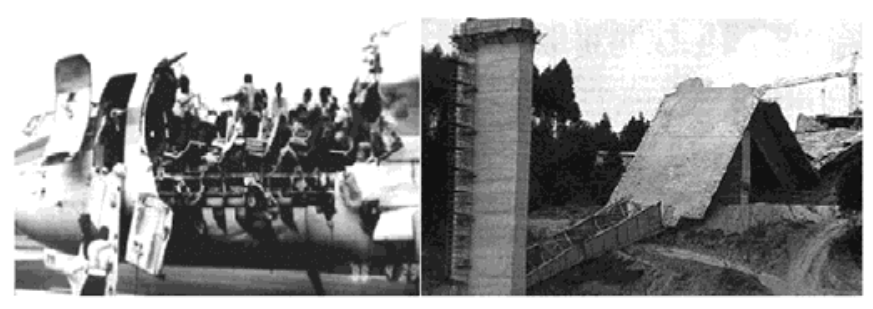

(a)

(b)

Figure 1. (a) The Aloha Airlines flight 243, (b) the Injaka bridge collapse, July 1998

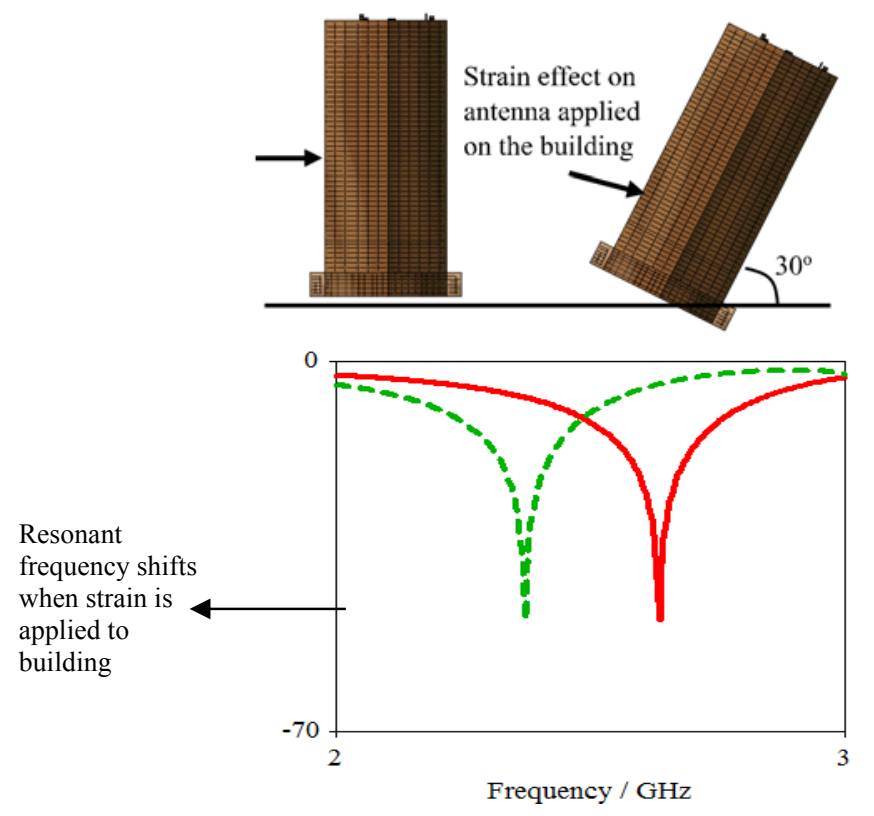

Figure 2. Concept microstrip patch based wireless structural health monitoring sensor 


\section{FLEXIBLE MICROSTRIP PATCH ANTENNA DESIGN AND DEVELOPMENT}

The most important parameters that need to specify to design Microstrip patch antenna are, antenna frequency of operation $(f c)$, permittivity or dielectric constant of the substrate $\left(\varepsilon_{r}\right)$, thickness or height of dielectric substrate $(h)$, and height of the conductor $(t)$. Other parameters include the width of the patch $(w)$, length of the patch, and width and length of the ground plane and substrate ( $W S$ and $W g$ ). In this project Microstrip patch antenna as a strain sensor will be designed. The objective is frequency of this antenna should shift according to the applied strain. In this project a felt will be used as a substrate which have permittivity of 1.44 and height of $3 \mathrm{~mm}$ and shield as a conductor which has Thickness: $0.17 \mathrm{~mm}$ and Conductivity $=1.18 \times 10^{5}$. Table 1 tabulated the antenna design specification.

In this design, the dual-band textile antenna candidate was selected to be an E-shaped patch antenna An E-shaped patch antenna is easily formed by cutting two slots from a rectangular shape. By cutting these slots from a patch the desired frequency will be achieved easily [3], gain, return loss and bandwidth of microstrip antenna can be improved also. The proposed antenna is designed for $1.8 \mathrm{GHz}$ and $2.4 \mathrm{GHz}$ frequencies. The felt and shield materials are used for conducting elements enable the antenna to be flexible, low profile and lightweight. To design dual band antenna first of all we calculated the parameters for single band antenna and then cut the slots of appropriate length at appropriate position to make it dual band. In our design firstly we calculate the parameters of the microstrip patch antenna to resonate at $2.4 \mathrm{GHz}$ by using the equations $1-6$ taking height of substrate $(h)=3 \mathrm{~mm}$ and dielectric constant $\left(\varepsilon_{\mathrm{r}}\right)=1.44$ The calculated parameters are summarized in Table 2, After getting the desired simulated results for $2.4 \mathrm{GHz}$ frequency, we went for cutting slot in the patch to make it resonate at another frequency also. Before getting the optimum simulated results in terms of return loss, resonant frequencies, bandwidth and impedance matching we have done the parametric simulation study of the designed antennas [4-5].

Step 1. Calculation of the width (W):

$$
W=\frac{C}{2 f_{r}} \sqrt{\frac{2}{\varepsilon_{r}+1}}
$$

Step 2: Calculation of effective dielectric constant: using equation:

$$
\varepsilon_{\text {reff }}=\frac{\varepsilon_{r}+1}{2}+\frac{\varepsilon_{r}-1}{2}\left[1+12 \frac{h}{w}\right]^{-\frac{1}{2}}
$$

Step 3: Calculation of the effective length $\left(L_{\text {eff }}\right)$ : equation 3 gives the effective length as:

$$
L_{e f f}=\frac{c}{2 f_{o} \sqrt{\varepsilon_{\text {reff }}}}
$$

Step 4: Calculation of the length extension $(\Delta L)$ :

$$
\Delta L=0.412 h \frac{\left(\varepsilon_{r e f f}+0.3\right)\left(\frac{W}{h}+0.264\right)}{\left(\varepsilon_{r e f f}-0.258\right)\left(\frac{w}{h}+0.8\right)}
$$

Step 5: Calculation of the actual length of the patch $(L)$ :

$$
L=L_{e f f}-2 \Delta L
$$

Step 6: Calculation of the ground plane dimensions ( $\mathrm{Lg}$ and $\mathrm{Wg})$ :

$$
\begin{aligned}
& L_{g}=6 h+L_{b}=6(3 \mathrm{~mm})+24.26 \mathrm{~mm}=52.36 \mathrm{~mm} \\
& W_{g}=6 h+W_{b}=6(3 \mathrm{~mm})+66.58 \mathrm{~mm}=94.58 \mathrm{~mm}
\end{aligned}
$$

The geometry of the patch antenna for dual-band operation is shown in Figure 3. Two slots are etched out from the patch to achieve the dual band operation. These slots make the patch to become and Eshaped microstrip patch antenna working with dual frequencies. The etching of slots leads to many 
parameters to be examined for dual-band operations. Shield conductor which has Thickness of $0.17 \mathrm{~mm}$ and Conductivity of $1.18 \times 105$ And Felt substrate is used to design this antenna with dielectric constant 1.44 and thickness of $3 \mathrm{~mm}$. The materials used for fabrication of the antenna is shield conductor of height of $0.17 \mathrm{~mm}$ with felt substrate of dielectric constant 1.44 and thickness of $3 \mathrm{~mm}$ the front view and back view of fabricated antenna is shown in Figure 4.

Table 1. Design specifications

\begin{tabular}{ll}
\hline Feature & Value \\
\hline Operating Frequency, $f$ & $2.45 \mathrm{GHz}$ \\
Efficiency & More than $50 \%$ \\
Radiating pattern & Directional \\
Directivity and gain & Moderate \\
Physical profile & Low profile and compact \\
Substrate & Felt \\
& Thickness: $3 \mathrm{~mm}$ \\
& Permittivity $=1.44$ \\
Conductor & Shielded \\
& Thickness: $0.17 \mathrm{~mm}$ \\
& Conductivity $=1.18 \times 10^{5}$ \\
\hline
\end{tabular}

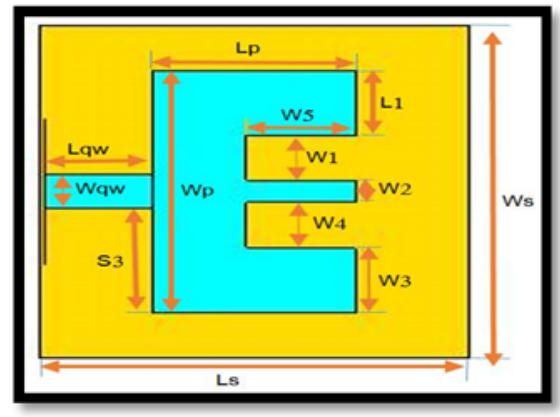

Figure 3. Geometry of E-Shape Antenna

Table 2. Calculated parameters

\begin{tabular}{cc}
\hline Parameters & Value $(\mathrm{mm})$ \\
\hline $\mathrm{L}_{1}$ & 28.2 \\
$\mathrm{~W}_{1}$ & 18.5 \\
$\mathrm{~W}_{2}$ & 10.85 \\
$\mathrm{~W}_{3}$ & 18.5 \\
$\mathrm{~W}_{4}$ & 16.85 \\
$\mathrm{~W}_{5}$ & 24 \\
$\mathrm{~W}_{\mathrm{qw}}$ & 8.5 \\
$\mathrm{~L}_{\mathrm{qw}}$ & 23.5 \\
$\mathrm{~S}_{3}$ & 30 \\
\hline
\end{tabular}

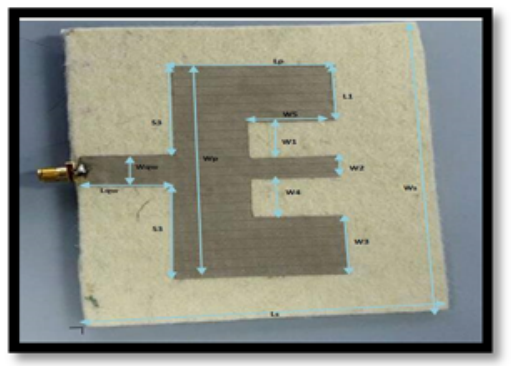

(a)

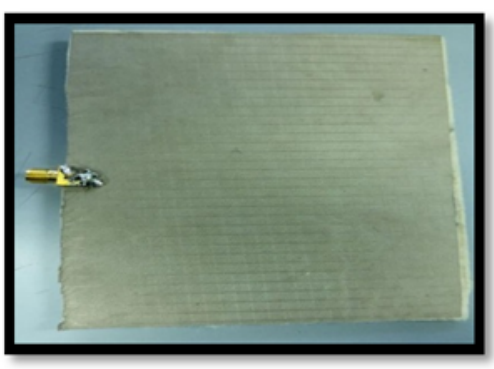

(b)

Figure 4. Fabricated E-Shaped Antenna, (a) the Front View of E-Shape antenna, (b) the rear view of E-Shape antenna showing the Ground plane 


\section{RESULTS AND ANALYSIS}

\subsection{E-Shape Antenna S-Parameter results}

The S-parameter plot shows the variation of return loss (in $\mathrm{dB}$ ) over a range of frequencies. Since at resonance the antenna is having the best impedance matching so the return loss would be minimum. The designed antenna resonates at $1.8 \mathrm{G}$ and 2.4 respectively. The return loss of $1.8 \mathrm{GHz}$ is $-12.9 \mathrm{~dB}$ and the return loss of $2.4 \mathrm{GHz}$ is $-22 \mathrm{~dB}$. Which covers the minimum required value of return loss of $-10 \mathrm{db}$, the bandwidth covered after first and second band are $60 \mathrm{MHz}$ and $180 \mathrm{MHz}$ respectively. The plot for return loss is found in Figure 5.

Measurement result drops almost at $1.8 \mathrm{GHz}$ and $2.45 \mathrm{GHz}$, while simulation actual result is $1.8 \mathrm{GHz}$ and $2.4 \mathrm{GHz}$. It shows that the measured value of return loss is $-14.9 \mathrm{~dB}$ for lower frequency band and $-34.2 \mathrm{~dB}$ for higher frequency band whereas the simulated value of return loss is $-13.12 \mathrm{~dB}$ and $-2.35 \mathrm{~dB}$ for lower and higher frequency band respectively. From the result we can see that the measured and simulated results are almost the same. It shows that the return loss increases at lower frequency and decreases at higher frequency. This is because of the soldering and feed that does not touch well at the ground plane, additionally this antenna is manual fabrication were it is difficult to achieve the same result as the simulation. The simulated bandwidth and measured bandwidth of the antenna is almost the same for lower frequency band and looks smaller bit for the higher frequency band. The measured value of the bandwidth is $60 \mathrm{kHz}(1.75 \mathrm{GHz}-$ $1.825 \mathrm{GHz})$ for lower frequency band and $13 \mathrm{MHz}(2.45 \mathrm{GHz}-2.32 \mathrm{GHz})$ for higher frequency band.

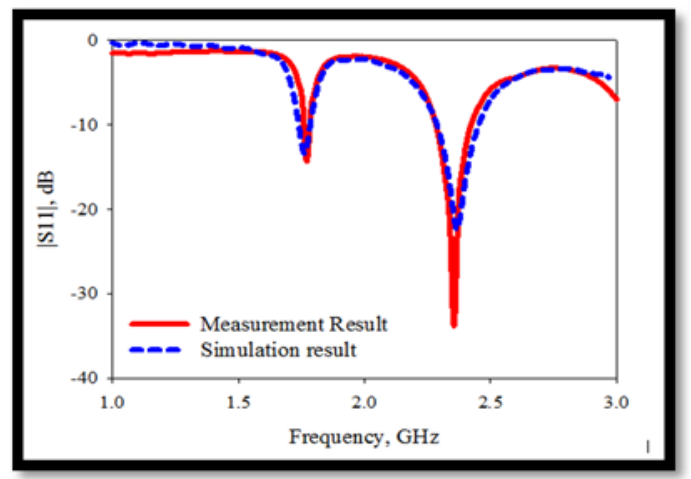

(a)

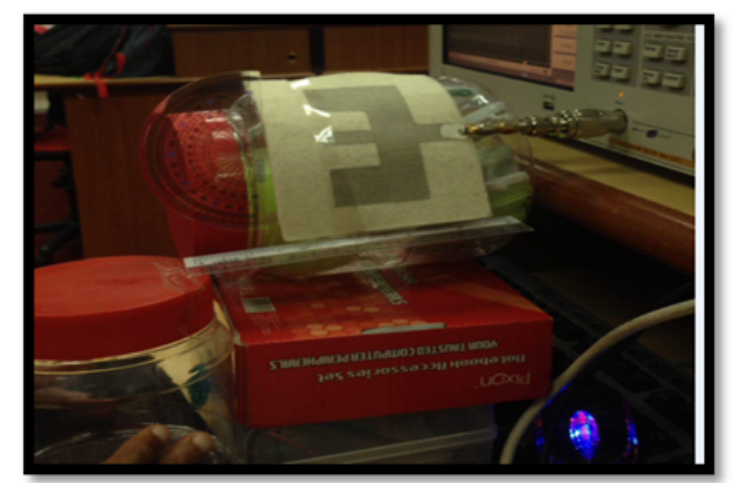

(b)

Figure 5. (a) Simulation and Measurement result, (b) Antenna under measurement test

\subsection{Bending Antenna Experiment for Structural Health Monitoring System}

Figure 6 shows the microstrip patch antenna undergo for strain measurement at different type of bending. It is shows the fabricated antenna connected to the FSMA and network analyser. Figure 6(a) shows the antenna is at 0 degree where no bending hence the frequency is not changing. After that we bend the antenna to 10 degree as shown in Figure 6(b), then we continue increasing the angle up to 55 degree as shown Figure 6(e). Figure 2 illustrates a typical building which was applied to strain, increasing the force applied to building increases the bending angle of the building. As at 0 degree bending, it is mean the microstrip patch is normal and there is no force being applied to the antenna as shown in Figure 6(a). Applying some force to the building causes to bend the antenna with the corresponding angle. If we increase the force it will cause more bending and increases the angle of the antenna.

Figure 7 shows the bending results from VNA, as we can see from the graph whenever we increase the angle or degree then the frequency will shift to right also. So in this condition we can say that bending and angle is directly proportional to each other. At the beginning the frequency was approximately from $1.8 \mathrm{GHz}$ to $2.4 \mathrm{GHz}$ which is shown black colour, and strain was not applied to the antenna so the antenna is in the normal no bending. Second the patch was bent 20degree and the frequency shifts from $(1.8 \mathrm{GHz}-$ $2.4 \mathrm{GHz})$ to $(1.875-2.49 \mathrm{GHz})$, as we increase the force the angle of incident will also be larger. In addition a 40degree bend shifts the frequency to $2.08-2,65 \mathrm{GHz}$. And lastly $55 \mathrm{degree}$ of bend will cause the largest shifting of this antenna. This data is summarized in Table 3. 
Table 3. Antenna angle bending vs frequency shift.

\begin{tabular}{cc}
\hline Antenna angle bending (degree) & Frequency shifting in $\mathrm{GHz}$ \\
\hline 0 & $1.8-2.4$ \\
10 & $1.875-2.49$ \\
20 & $1.9-2.59$. \\
40 & $2.08-2.65$. \\
55 & $2.108-2.78$. \\
\hline
\end{tabular}

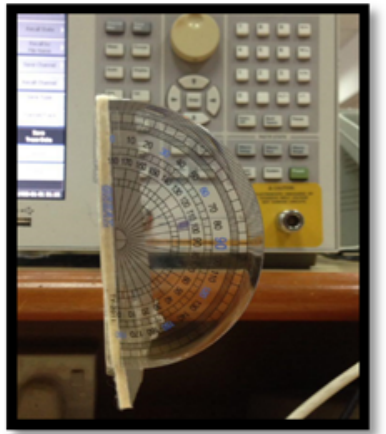

(a) 0 degree

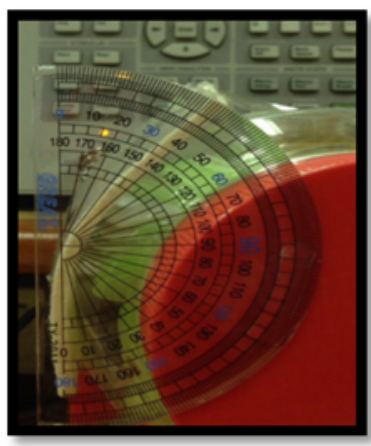

(d) 35 degree

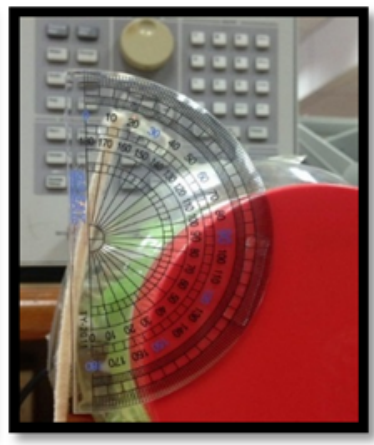

(b) 20 degree

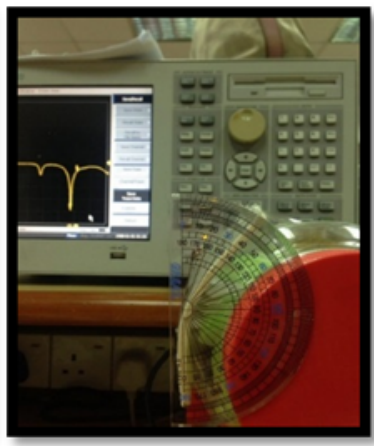

(e) 40 degree

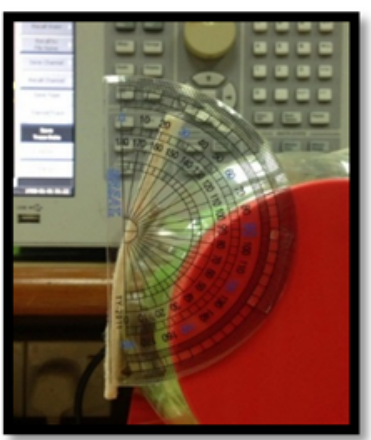

(c) 30 degree

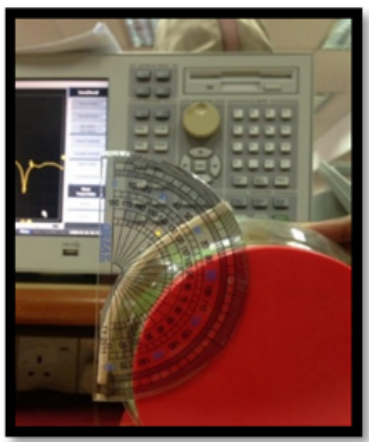

(f) 55 degree

Figure 6. E-Shape antenna under different bending measurement test

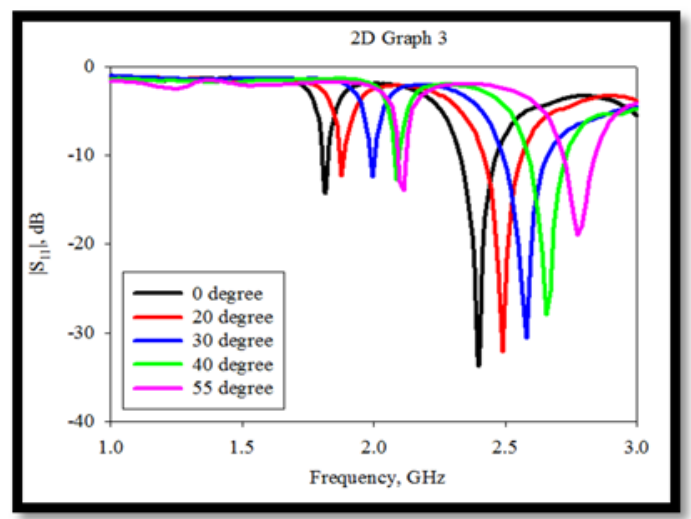

Figure 7. Bending result from 0 degree to 55 degree

\section{CONCLUSION}

The main objective of this research was to investigate the feasibility of measuring strain using microstrip patch antennas. Which is compact and have high gain antenna that is suitable for structural health monitoring application. The relationship between the shift of the resonant frequency of a rectangular microstrip patch antenna and the strain applied to the antenna is discussed for five different bending angles. 
The results indicate that the resonant frequency of the antenna shifts by applying strain that shows increasing the bending angle increases the frequency shift. Strain measurement using slotted rectangular microstrip patch antenna proposed in this design is another area of development which will have important advantages over current strain sensors. Hence in the future this design could be developed by adding cross slots to measure the direction of the strain also and how much strain is applied to the rectangular patch antenna, to become more interesting.

\section{ACKNOWLEDGEMENTS}

The authors gratefully acknowledge use of the services and facilities of the Advanced Communication Engineering Centre (ACE) CoE, School of Computer and Communication Engineering, Universiti Malaysia Perlis (UniMAP). This project also been funded by Fundamental Research Grant Scheme (FRGS) 9003-00545.

\section{REFERENCES}

[1] Z. Yinhai, et al., "A Novel SVPWM Modulation Scheme," in Applied Power Electronics Conference and Exposition, 2009. APEC 2009. Twenty-Fourth Annual IEEE, 2009, pp. 128-131.

[2] Daliri, Ali, et al. "Circular microstrip patch antenna strain sensor for wireless structural health monitoring." Proceedings of the World Congress on Engineering, vol. 2, 2010.

[3] Widodo, Achmad, et al. "Development of Wireless Smart Sensor for Structure and Machine Monitoring." TELKOMNIKA (Telecommunication Computing Electronics and Control), 2013; 11 (2): 417-424.

[4] Suryanita, Reni. "Intelligent Bridge Seismic Monitoring System Based on Neuro Genetic Hybrid." TELKOMNIKA (Telecommunication Computing Electronics and Control), 2017; 15 (4): 1830 1840.

[5] Putra, Seno Adi, et al. "Conceptual Design of Multi-agent System for Suramadu Bridge Structural Health Monitoring System." TELKOMNIKA (Telecommunication Computing Electronics and Control), 2015; 13 (3): 1079-1088.

[6] R. Matsuzaki, M. Melnykowycz, and A. Todoroki, "Antenna/sensor multifunctional composites for the wireless detection of damage," Compos. Sci. Technol., vol. 69, no. 15-16, pp. 2507-2513, 2009.

[7] Downey, Austin, et al. "Damage detection, localization and quantification in conductive smart concrete structures using a resistor mesh model." Engineering Structures, no.148, pp. 924-935, 2017.

[8] U. Tata, H. Huang, R. L. Carter, and J. C. Chiao, "Exploiting a patch antenna for strain measurements," Meas. Sci. Technol., vol. 20, no. 1, pp. 15201, 2009.

[9] R. Di Sante, "Fibre Optic Sensors for Structural Health Monitoring of Aircraft Composite Structures: Recent Advances and Applications," Sensors (Basel), vol. 15, no. 8, pp. 18666-713, 2015.

[10] W. Clem and L. Zhang, "Fact behind Building Collapse in Shanghai," pp. 16, 2009.

\section{BIOGRAPHIES OF AUTHORS}

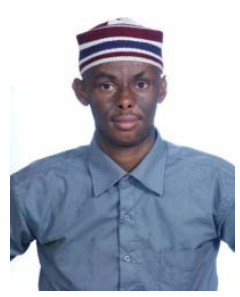

Hamse abdillahi haji was born in Hargeisa, Somalia, in 1994. He received the Bachelor of Engineering (Honours) (Communication Engineering) degree from University Malaysia Perlis, Malaysia in 2017. During his studies, he is a top student in class, consequently upon graduation he being awarded the Vice-Chancellor Gold Medal Award at the 12th Convocation Ceremony of UniMAP. His current interest are microstrip patch antenna and microwave research area.

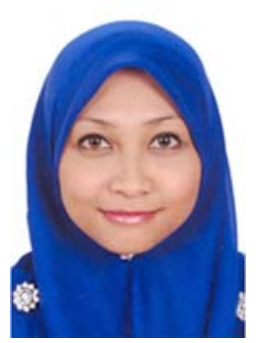

Dr. Saidatul Norlyana Azemi obtained her Ph.D in 2014 from Royal Melbourne Institute Technology (RMIT) University, Melbourne Australia. She has received the Masters of Science in Communication Engineering in 2010 from University Malaysia Perlis, Malaysia. Previously, she obtained her first degree from University Malaysia Perlis, Malaysia, with Honors, in Communication Engineering, graduating in 2007. In RMIT University Melbourne Australia, Dr. Saidatul was a winner for Poster and Oral presentation two year in a row during Higher Degree by Research Conference's day RMIT as well as School of Electrical and Computer Engineering (SECE) Postgraduate Research Day. Dr. Saidatul was the recipient of the Best Student Paper Award presented at the Malaysian Technical Universities Conference on Engineering and Technology (MUCET 2017). She has published several impact factor journals, national and international conference papers. Shee is currently a Senior Lecturer at the School of Computer and Communication Engineering (SCCE), Universiti Malaysia Perlis (UniMAP). Her research interest focus on 3-D and 2D Frequency Selective Surface, 3-D antenna structure, antenna design and diversity, dielectric materials, wireless network, and RF \& microwave design. 


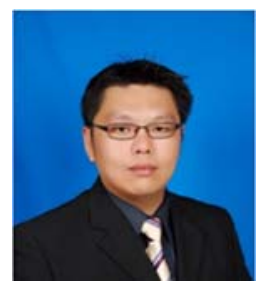

Ping Jack Soh, C.Eng, was born in Sabah, Malaysia. He received the Bachelor and Master degrees in Electrical Engineering (Telecommunication) from Universiti Teknologi Malaysia (UTM) in 2002 and 2006, respectively, and the PhD degree in Electrical Engineering from KU Leuven, Belgium in 2013. He is currently an Associate Professor at the School of Computer and Communication Engineering (SCCE), Universiti Malaysia Perlis (UniMAP). He researches and publishes actively in his areas of interest: wearable antennas, arrays, metasurfaces and systems; on-body communication; electromagnetic safety and absorption; and wireless and radar techniques for healthcare applications. Dr. Soh was the recipient of the IEEE Antennas and Propagation Society (AP-S) Doctoral Research Award in 2012, the IEEE Microwave Theory and Techniques Society (MTT-S) Graduate Fellowship for Medical Applications in 2013 and the International Union of Radio Science (URSI) Young Scientist Award in 2015. He was also the Second Place Winner of the IEEE Presidents' Change the World Competition and IEEE MTT-S Video Competition, both in 2013. He is a Chartered Engineer registered with the UK Engineering Council; a Senior Member of the IEEE, a Member of the IET, ACES and URSI; and a Graduate Member of the BEM and the IEM. He also serves in the IEEE MTT-S EduComm, and the IEEE MTT-S M\&S Committee.

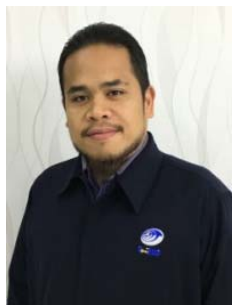

Azremi Abdullah Al-Hadi was born on August 26, in Michigan, United States of America. He received the Master of Science degree in communication engineering from Birmingham University, United Kingdom in 2004 and the Doctor of Science in Technology degree from Aalto University, Finland in 2013. His current research interests include design and performance evaluation of multi-element antennas, mobile terminal antennas and their user interactions, and wireless propagation. He is currently working as an Associate Professor and holds position as Dean of the School of Computer and Communication Engineering, Universiti Malaysia Perlis (UniMAP). He has been with the school since 2002. He is active in volunteer work with IEEE Malaysia Section, acting as the Senior Member of IEEE, executive committee in the IEEE Antenna Propagation / Microwave Theory techniques / Electromagnetic Compatibility (AP/MTT/EMC) Malaysia Chapter and Counselor for the IEEE UniMAP Student Branch. He is the Chartered Engineer of the Institution of Engineering and Technology (IET), UK and the member of the Board of Engineers Malaysia (BEM), Malaysia. Dr. Azremi was the recipient of the Best Student Paper Award presented at the 5th Loughborough Antennas and Propagation Conference (LAPC 2009) and the CST University Publication Award in 2011.

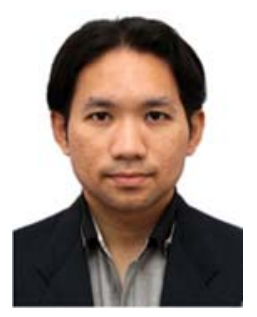

Mohd Faizal Jamlos is an Associate Professor in Advanced Communication Engineering Centre (ACE), School of Computer and Communication Engineering at the Universiti Malaysia Perlis, Malaysia. He obtained his Ph.D in 2010 from Universiti Teknologi Malaysia, Malaysia and M.Eng. degree in Electrical and Electronic from University of Adelaide, Australia in 2008. His first degree is from Universiti Malaysia Perlis, Malaysia, with Honours, in Computer Engineering in 2006. He has authored over 200 publications, including 80 peer-reviewed journal papers, 129 conference papers, 3 book chapters and five patents. He has served as a reviewer for Transaction Microwave Theory \& Technique, Transaction Antenna \& Propagation, Progress in Electromagnetics Research, IET Microwaves and TPC for few international conferences. His current research interests include Advanced Microwaves Metamaterials, Microwave Imaging, On-platform Electromagnetism of automotive and V2X Communication system and IoT applications. He has been recognized in providing training and consultations on Test and Measurement systems and Microwave \& RF Transceiver Design to various companies and universities. He is a Senior Member of IEEE, Malaysia Medical Researcher (NMRR), and Professional Engineer of Board of Engineers Malaysia. He also appointed as Academy Trainer of MikroTik and certified for Network Associate, Traffic Control Engineer and Routing Engineer.

Indonesian J Elec Eng \& Comp Sci, Vol. 10, No. 3, June 2018 : 917 - 924 